\title{
Influence of thermal annealings in different atmospheres on the band-gap shift and resistivity of CdS thin films
}

\author{
S. A. Tomás, O. Vigil, ${ }^{a)}$ J. J. Alvarado-Gil, R. Lozada-Morales, ${ }^{\text {b) }}$ and O. Zelaya-Angel \\ Departamento de Física, Centro de Investigación y de Estudios Avanzados del IPN, Apdo. Postal 14-740, \\ México D.F. 07000, México \\ H. Vargas ${ }^{\mathrm{c})}$ \\ Programa Multidisciplinario en Ciencias Aplicadas y Tecnologia Avanzada, Centro de Investigación y de \\ Estudios Avanzados del IPN, Apda. Postal 14-740, México D.F. 07000, México
}

\begin{abstract}
A. Ferreira da Silva
Instituto Nacional de Pesquisas Espaciais-INPE, Laboratorio Associado de Sensores e Materiais-LAS, CP 515,12201-970 Sao Jose dos Campos, S.P., Brazil
\end{abstract}

(Received 16 December 1994; accepted for publication 5 May 1995)

\begin{abstract}
We study by photoacoustic spectroscopy the band-gap shift effect of CdS films. The CdS films were grown by chemical bath deposition and exposed to different annealing atmospheres over a range of temperature in which the sample structure changes. We show the band-gap evolution and resistivity as a function of temperature of thermal annealing and determine the process that produces the best combination of high band-gap energy and low resistivity. (c) 1995 American Institute of Physics.
\end{abstract}

\section{INTRODUCTION}

The study of heterojunctions has become a subject of intense activity in solid state research. Apart from their utility in the fabrication of transistors and diodes, heterojunctions play an important role in the development of solar cell technology. In particular, CdS/CdTe heterojunctions represent one of the principal candidates for low-cost and high conversion-efficiency solar cells. ${ }^{1}$ In this type of solar cell, fabrication of CdS films with low resistivity is very important because it helps to diminish the dispositive sheet resistance and to obtain the space charge region in the active zone, i.e., in the CdTe film.

It is known that CdS exists in either of two different structural phases, namely, a highly stable hexagonal phase and a metastable cubic phase. Cardona et al. have demonstrated by means of room-temperature reflectivity measurements that such phases have a band-gap energy differing by less than $0.1 \mathrm{eV}^{2}$ Cubic phase CdS films display a band-gap shift (BGS) effect that is dependent on the temperature and annealing atmosphere. The influence of temperature on $\mathrm{Si}$ films was first reported by Balkanski et al. ${ }^{3}$ Subsequently, because of its technological importance in optoelectronic design, the BGS effect of intrinsic and extrinsic semiconductors has been extensively investigated. ${ }^{4-8}$ Recently, ZelayaAngel $e t a l .{ }^{9}$ have reported the first study of the influence of the annealing atmosphere on the BGS effect in CdS films. However, it is worth noting that such a BGS effect, as well as the growth procedures to obtain CdS films in either of the phases, are not well understood up to now.

In this article, we study the influence of the temperature of thermal annealing (TTA), in different annealing atmospheres, on the band-gap shift and resistivity in CdS thin films. The annealing atmospheres include $\mathrm{Ar}, \mathrm{Ar}+\mathrm{S}_{2}$,

\footnotetext{
") Permanent address: Physics Faculty, U. of La Havana, La Havana, Cuba. b) Also at ECFM, Depto. de Optoelectrónica, U.A.P., Puebla, México.

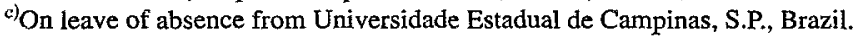

$\mathrm{H}_{2}+\mathrm{In}, \mathrm{H}_{2}$, and air, in the temperature range $200-450{ }^{\circ} \mathrm{C}$ We show the interesting and technologically important combination of low resistivity CdS thin films with high-energy gap. The band-gap shift is studied by photoacoustic spectroscopy (PAS) because this technique allows us to obtain spectra that clearly show the BGS effect. ${ }^{9-12}$

\section{EXPERIMENT}

Cadmium sulfide thin films of approximately $0.25 \mu \mathrm{m}$ thickness were prepared by the chemical bath deposition (CBD) method. The chemical bath was an aqueous solution of $\mathrm{CdCl}_{2}, \mathrm{KOH}, \mathrm{NH}_{4} \mathrm{NO}_{3}$, and $\mathrm{CS}\left[\mathrm{NH}_{2}\right]_{2}$ (thiourca). The solution was maintained at $(80 \pm 3){ }^{\circ} \mathrm{C}$ and continuously stirred in order to ensure a homogeneous distribution of the chemical compounds. ${ }^{13}$

Postdeposition thermal treatments of the samples were performed in a quartz tube placed into a hot wall furnace. Using the furnace temperature profile, CdS samples were heated simultaneously in the temperature range $200-450^{\circ} \mathrm{C}$. For the Ar gas and $\mathrm{Ar}$ gas $+\mathrm{S}_{2}$ vapor flux annealings, the CdS samples wcre heatcd for $28 \mathrm{~h}$ at 208,260,296,353,398, and $447^{\circ} \mathrm{C}$ (for $\mathrm{Ar}+\mathrm{S}_{2}$, the last TTA was $418^{\circ} \mathrm{C}$ ). The $\mathrm{S}_{2}$ vapor flux was obtained by placing a boat containing sulfur at $190^{\circ} \mathrm{C}$. For the $\mathrm{H}_{2}$ gas, $\mathrm{H}_{2}$ gas $+\mathrm{In}$ vapor flux, and air annealings, the CdS samples were kept at 200, 250,300,350, 400 , and $450^{\circ} \mathrm{C}$ for $1 \mathrm{~h}$. For $\mathrm{H}_{2}+\mathrm{In}$, a boat containing In was placed at $330^{\circ} \mathrm{C}$, whereas for the $\mathrm{H}_{2}$ annealing, a flow of $\mathrm{H}_{2}$ gas was kept for $30 \mathrm{~min}$ before placing the samples. The pressure for all the treatments was about $1 \mathrm{~atm}$.

Photoacoustic absorption spectra of the films were obtained in the region $400-700 \mathrm{~nm}$ by the use of a standard photoacoustic spectrometer fitted with a $1000 \mathrm{~W}$ Xenon lamp (Oriel). The radiation from the lamp was focused onto a variable-frequency light chopper held at $17 \mathrm{~Hz}$ and placed at the entrance slit of a monochromator. The monochromatic light was focused onto the samples placed into a closed pho- 


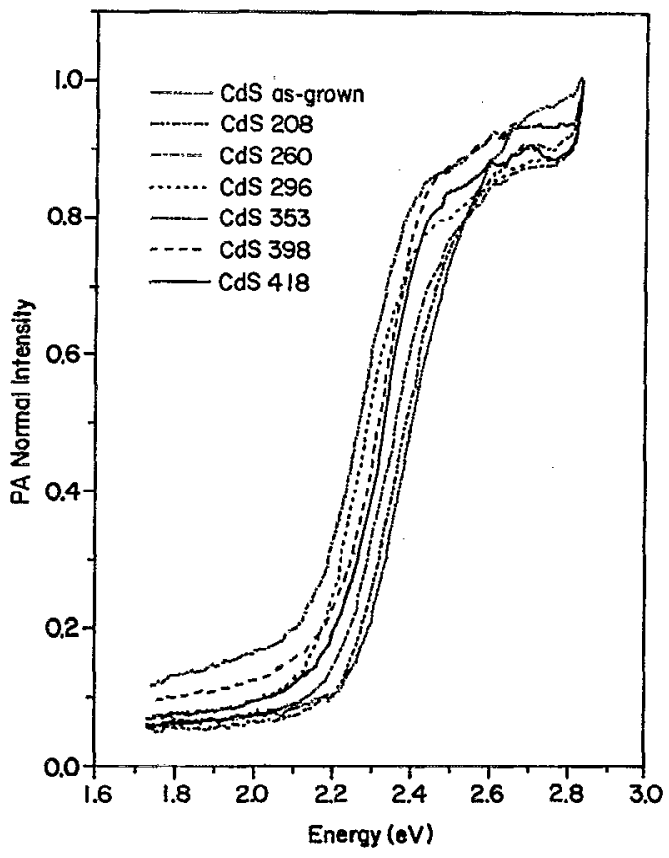

FIG. 1. PA normal intensity as a function of energy for CdS films annealed in $\mathrm{Ar}+\mathrm{S}_{2}$ atmosphere for different TTA.

toacoustic cell. The photoacoustic signal was preamplified and, subsequently, sent to a lock-in amplifier.

Resistivity measurements were performed at room temperature by the two probe method for high resistivity films and the four probe method for low resistivity films. The four probe technique was not satisfactory for high resistivity films because the order of magnitude of the film resistance and the electrometer input impedance was the same. Ohmic contacts were evaporated on the film surface in order to measure the lateral resistivity.

\section{RESULTS AND DISCUSSION}

In Fig. 1, we show the photoacoustic (PA) spectra for the as-grown CdS sample and the set of CdS films annealed in the $\mathrm{Ar}+\mathrm{S}_{2}$ atmosphere. We assume that the band-gap energy is given by the inflexion point in the spectrum. The values of the band-gap energy (BGE) for samples annealed in the Ar and $\mathrm{Ar}+\mathrm{S}_{2}$ atmospheres are displayed in Table I. The results

TABLE I. Values of the band-gap energy $E_{g}$ and band-gap shift $\Delta E_{g}$ as a function of temperature of thermal annealing for $\mathrm{Ar}$ and $\mathrm{Ar}+\mathrm{S}_{2}$ annealings.

\begin{tabular}{cccccc}
\hline & \multicolumn{3}{c}{$\mathrm{Ar}$} & & \multicolumn{2}{c}{$\mathrm{Ar}+\mathrm{S}_{2}$} \\
\cline { 2 - 3 } \cline { 5 - 6 } $\operatorname{TTA}\left({ }^{\circ} \mathrm{C}\right)$ & $E_{g}(\mathrm{eV})$ & $\Delta E_{g}(\mathrm{eV})$ & & $E_{g}(\mathrm{eV})$ & $\Delta E_{g}(\mathrm{eV})$ \\
\hline 80 (as-grown) & 2.42 & $\ldots$ & & 2.42 & $\cdots$ \\
208 & 2.40 & 0.02 & & 2.40 & 0.02 \\
260 & 2.36 & 0.06 & & 2.37 & 0.05 \\
296 & 2.35 & 0.07 & & 2.29 & 0.13 \\
353 & 2.30 & 0.12 & & 2.28 & 0.14 \\
398 & 2.29 & 0.13 & & 2.33 & 0.09 \\
418 & & & 2.34 & 0.08 \\
447 & 2.31 & 0.11 & & \\
\hline
\end{tabular}

TABLE II. Values of the band-gap energy $E_{g}$ and band-gap shift $\Delta E_{g}$ as a function of temperature of thermal annealing for $\mathrm{H}_{2}, \mathrm{H}_{2}+\mathrm{In}$, and air annealings.

\begin{tabular}{|c|c|c|c|c|c|c|}
\hline \multirow[b]{2}{*}{$\operatorname{TTA}\left({ }^{\circ} \mathrm{C}\right)$} & \multicolumn{2}{|c|}{$\mathrm{H}_{2}$} & \multicolumn{2}{|c|}{$\mathrm{H}_{2}+\mathrm{In}$} & \multicolumn{2}{|c|}{ Air } \\
\hline & $E_{\mathrm{g}}(\mathrm{eV})$ & $\Delta E_{g}(\mathrm{eV})$ & $E_{g}(\mathrm{eV})$ & $\Delta E_{\mathrm{g}}(\mathrm{eV})$ & $E_{g}(\mathrm{eV})$ & $\Delta E_{g}(\mathrm{eV})$ \\
\hline 80 (as-grown) & 2.42 & $\cdots$ & 2.42 & $\cdots$ & 2.42 & $\cdots$ \\
\hline 200 & 2.40 & 0.02 & 2.40 & 0.02 & 2.37 & 0.05 \\
\hline 250 & 2.39 & 0.03 & 2.37 & 0.05 & 2.34 & 0.08 \\
\hline 300 & 2.37 & 0.05 & 2.34 & 0.08 & 2.27 & 0.15 \\
\hline 350 & 2.31 & 0.11 & 2.28 & 0.14 & 2.25 & 0.17 \\
\hline 400 & 2.27 & 0.15 & 2.27 & 0.15 & 2.26 & 0.16 \\
\hline 450 & 2.27 & 0.15 & 2.28 & 0.14 & 2.26 & 0.16 \\
\hline
\end{tabular}

for samples annealed in the $\mathrm{H}_{2}, \mathrm{H}_{2}+\mathrm{In}$, and air atmospheres are given in Table II.

In Fig. 2, we show the BGE as a function of TTA for the samples annealed in the $\mathrm{Ar}+\mathrm{S}_{2}$ atmosphere. Note that the BGE decreases as the TTA increases for the temperature range $80-350^{\circ} \mathrm{C}$. At roughly $350^{\circ} \mathrm{C}$, we find that the $\mathrm{BGE}$ reaches a minimum. This effect carries down the BGE from its $2.42 \mathrm{eV}$ initial value to $2.28 \mathrm{eV}$. For temperatures above $350{ }^{\circ} \mathrm{C}$, the BGE increases up to $2.35 \mathrm{eV}$ at $418^{\circ} \mathrm{C}$. This narrowing-widening-like behavior presented by CBD-CdS films annealed in an $\mathrm{Ar}+\mathrm{S}_{2}$ atmosphere has been attributed to the transition from the cubic to the hexagonal phase, which is assumed to occur at the temperature corresponding to the minimum BGE. ${ }^{9}$ TTA coefficients of the BGE have been found to have values of approximately $10^{-4} \mathrm{eV} / \mathrm{TTA}$ (K) in the linear region of the data. ${ }^{14}$ The magnitude of these coefficients generally agree with those reported for other materials, e.g., $\mathrm{Si}, \mathrm{Ge}, \mathrm{GaAs}$, and $\mathrm{MgI}_{2} .{ }^{14,15}$

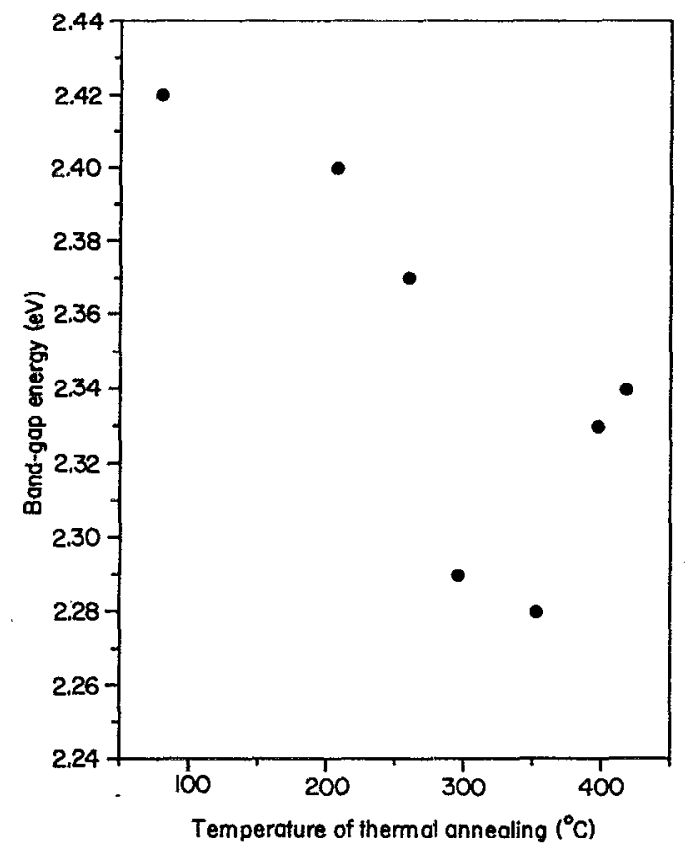

FIG. 2. TTA dependence of band-gap energy for CdS annealed in $\mathrm{Ar}+\mathrm{S}_{2}$ atmosphere. 


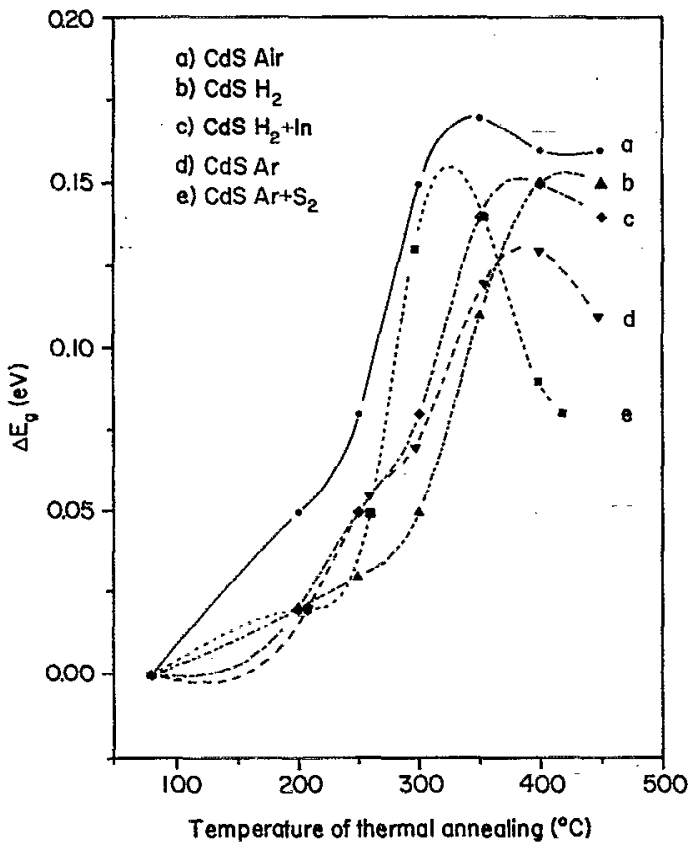

FIG. 3. TTA dependence of band-gap shift for CdS annealed in different atmospheres.

With respect to the other annealing atmospheres, we found that samples display only a narrowing-like behavior (see Tables I and II). For some of these annealings, the decrease in the BGE is faster or slower and the samples reach a higher or lower minimum value than when exposed to $\mathrm{Ar}+\mathrm{S}_{2}$. However, it is very important to point out that none of the atmospheres produce a clear widening-like behavior as $\mathrm{Ar}+\mathrm{S}_{2}$ does. On the contrary, all of them cause a stable tendency above the temperature corresponding to the minimum BGE. These results are shown in Fig. 3, where the BGS, given by

$$
\Delta E_{g}(\mathrm{TTA})=E_{g}\left(80^{\circ} \mathrm{C}\right)-E_{g}(\mathrm{TTA}),
$$

is plotted as a function of TTA. Here, $E_{g}\left(80^{\circ} \mathrm{C}\right)$ is the band-gap energy of the as-grown samples. Notice that, among the investigated annealing procedures, air produces the highest $\Delta E_{g}$ values. Its maximum value $\Delta E_{g}=0.17 \mathrm{eV}$ occurs at approximately $350^{\circ} \mathrm{C}$. Also, note that only the $\mathrm{Ar}+\mathrm{S}_{2}$ annealing produces a considerable diminution of the BGS, $\Delta E_{g}$, after having reached the maximum value.

In view of our interest in finding the thermal process that produces CBD-CdS films with the best combination of high band-gap energy and low resistivity, let us turn our attention to the electrical resistivity as a function of TTA. We describe only the typical behavior displayed by the samples because all of the annealing atmospheres have produced similar effects in them. The resistivity of as-grown samples measured $\rho=2.3 \times 10^{7} \Omega \mathrm{cm}$. For the annealed samples, the increase in the TTA caused a decrease in the resistivity until it reached a minimum value (as we can see in Table III, this minimum value becomes nine orders of magnitude smaller for $\mathrm{H}_{2}+\mathrm{In}$ samples than for as-grown samples). For temperatures above
TABLE III. Minimum resistivity and corresponding $E_{\mathrm{g}}$ as a function of temperature for thermal annealing in different atmospheres.

\begin{tabular}{llll}
\hline Annealing & $\begin{array}{c}\text { Minimum } \rho \\
(\Omega \mathrm{cm})\end{array}$ & $\begin{array}{c}E_{g} \\
(\mathrm{eV})\end{array}$ & $\begin{array}{c}\text { TTA } \\
\left({ }^{\circ} \mathrm{C}\right)\end{array}$ \\
\hline Air & $1.0 \times 10^{3}$ & 2.27 & 300 \\
$\mathrm{Ar}+\mathrm{S}_{2}$ & $1.9 \times 10^{3}$ & 2.29 & 296 \\
$\mathrm{Ar}$ & $2.5 \times 10^{2}$ & 2.30 & 353 \\
$\mathrm{H}_{2}$ & 0.15 & 2.37 & 300 \\
$\mathrm{H}_{2}+\mathrm{In}$ & 0.05 & 2.37 & 250 \\
\hline \hline
\end{tabular}

this region, the resistivity increased again. As shown in Table III, $\rho$ (TTA) assumes a minimum value dependent on the annealing atmosphere.

The $\mathrm{Ar}+\mathrm{S}_{2}^{*}$ annealing diminishes the resistivity by increasing the grain size, therefore the number of grain boundaries decreased in the films. On the other hand, the Ar annealing increases the grain size and produces a large amount of sulfur vacancies as a consequence of the nonequilibrium conditions. In the air annealing, the presence of oxygen creates both $\mathrm{CdO}$ and $\mathrm{CdSO}_{4}$ layers on the surface, increasing slightly the resistivity of the films compared to the Ar case. ${ }^{16}$ The thermal treatments in $\mathrm{H}_{2}$ and $\mathrm{H}_{2}+$ In have the advantage of containing $\mathrm{H}_{2}$, which is a strong agent for grain boundary passivation by oxygen chemisorption. ${ }^{17,18}$ The presence of $\mathrm{H}_{2}$ causes the resistivity to decrease by 4 and 5 orders of magnitude, respectively, compared to the $\mathrm{Ar}+\mathrm{S}_{2}$ case.

In order to simultaneously consider the band-gap energy and the resistivity, we define

$$
\xi(\text { TTA })=\frac{\Delta \rho(\text { TTA })}{\Delta E_{g}(\text { TTA })}=\frac{\rho\left(80^{\circ} \mathrm{C}\right)-\rho(\text { TTA })}{E_{g}\left(80^{\circ} \mathrm{C}\right)-E_{g}(\mathrm{TTA})} .
$$

Since $E_{g}\left(80^{\circ} \mathrm{C}\right)$ is larger than $E_{g}(\mathrm{TTA})$, a large band-gap energy $E_{g}$ (TTA) is equivalent to a small value for $\Delta E_{g}$ (TTA). Similarly, a low resistivity $\rho($ TTA) implies a high value for $\Delta \rho$ (TTA). It follows from Eq. (2) that the higher the value of $\xi$ (TTA), the better the combination of high $E_{g}$ (TTA) and low $\rho$ (TTA). Accordingly, $\xi$ (TTA) characterizes the annealed samples and allows us to identify both the atmosphere and the TTA that produce optimum conditions of high band-gap energy and low resistivity. We should observe that $\xi(T T A)$ is basically governed by $\Delta \rho$ (TTA) [because of its high values compared to the values of $\Delta E_{g}$ (TTA)]. This gives us insight into the TTA that should be investigated first, namely, those which produce high $\Delta \rho($ TTA $)$ values in the samples.

We have calculated $\xi$ (TTA) for all of the annealing atmospheres. With the highest values, shown in Table IV, we

TABLE IV. Maximum value of $\xi(T T A)$ in different annealing atmospheres.

\begin{tabular}{lcc}
\hline Annealing & $\begin{array}{c}\text { Highest } \xi \\
\left(10^{8} \Omega \mathrm{cm} / \mathrm{eV}\right)\end{array}$ & $\begin{array}{l}\text { TTA } \\
\left({ }^{\circ} \mathrm{C}\right)\end{array}$ \\
\hline Air & 1.53 & 300 \\
$\mathrm{Ar}+\mathrm{S}_{2}$ & 1.76 & 296 \\
$\mathrm{Ar}$ & 2.09 & 447 \\
$\mathrm{H}_{2}$ & 4.59 & 300 \\
$\mathrm{H}_{2}+\mathrm{In}$ & 4.60 & 250 \\
\hline
\end{tabular}




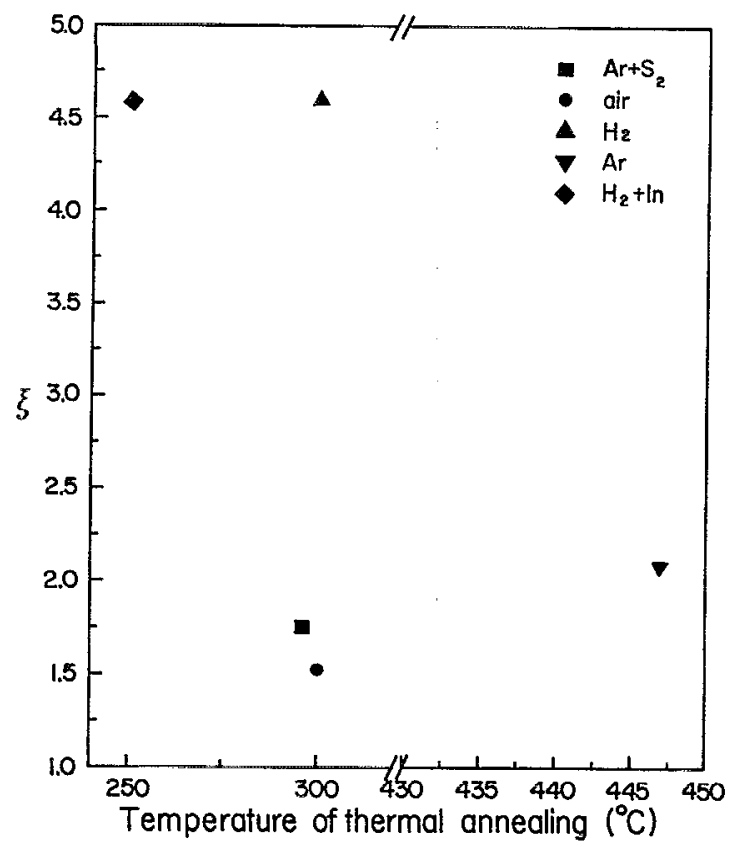

FIG. 4. Maximum value of (TTA) for different annealing atmospheres.

found the figure of merit illustrated in Fig. 4. This figure shows that, among the analyzed annealings, the $\mathrm{H}_{2}$ and $\mathrm{H}_{2}+\mathrm{In}$ atmospheres produce the best combination of low resistivity and high band-gap energy. In particular, the $\mathrm{H}_{2}+\mathrm{In}$ annealing is slightly better than the $\mathrm{H}_{2}$ annealing. Its maximum value for $\xi=4.6 \times 10^{\circ} \Omega \mathrm{cm} / \mathrm{eV}$ occurs at $250^{\circ} \mathrm{C}$. The measured resistivity for this sample was $\rho=5 \times 10^{-2}$ $\Omega \mathrm{cm}$. A similar value has been reported ${ }^{19}$ for a CdS crystal grown by the melt, using the Tamman method in Ar gas at around $110 \mathrm{~atm}$ of pressure. Moreover, for the $\mathrm{Ar}+\mathrm{S}_{2}$ atmosphere, the minimum resistivity is $\rho=1.9 \times 10^{3} \Omega \mathrm{cm}$. This resistivity is roughly reproduced $\left(2.3 \times 10^{3} \Omega \mathrm{cm}\right)$ for a normal CdS crystal only at $4.2 \mathrm{~K} .^{19}$

$\mathrm{X}$-ray diffraction patterns show that all the annealed samples present a slight interplanar-distance increase compared to the as-grown samples, but only the samples exposed to the $\mathrm{Ar}$ and $\mathrm{Ar}+\mathrm{S}_{2}$ annealings undergo a cubic to hexagonal phase transition. On the other hand, the samples annealed in the $\mathrm{H}_{2}, \mathrm{H}_{2}+\mathrm{In}$ and air atmospheres preserve the same structural phase along the complete thermal process. ${ }^{17}$ The mechanism that explains this microstructural behavior is under study at present.

Photoluminescence (PL) spectra of CdS samples an- nealed in $\mathrm{Ar}$ and $\mathrm{Ar}+\mathrm{S}_{2}$ atmospheres present a shift of the luminescent peaks as a function of TTA. This shift has been interpreted as an evidence of evolution from $S_{2}$ vacancies to interstitial $S_{2}$ formation. ${ }^{17}$ For these annealing atmospheres, interstitial $S_{2}$ becomes part of the hexagonal structure itself. Thus far, PL spectra of CBD-CdS samples annealed in $\mathrm{H}_{2}$, $\mathrm{H}_{2}+\mathrm{In}$, and air atmospheres have not been obtained.

In summary, we have found that CBD-CdS thin films display low resistivity and high band-gap energy when exposed to an $\mathrm{H}_{2}+\mathrm{In}$ annealing atmosphere at $250^{\circ} \mathrm{C}$. CdS films with these characteristics play an important role because they are used in the development of low resistivity $\mathrm{CdS} / \mathrm{CdTe}$ solar cells with high quantum efficiency. Thus, they are real candidates for high conversion-efficiency solar cells.

\section{ACKNOWLEDGMENTS}

This work was partially supported by the Mexican agency CONACYT. The authors are grateful to W. A. Wassam, Jr. for enlightening discussions. H.V. and A.F.S. acknowledge the Brazilian agency $\mathrm{CNP} q / \mathrm{MCT}$ for financial support. A.F.S. and O.V. acknowledge CINVESTAV-IPN for its hospitality.

${ }^{1}$ J. Britt and C. Ferekides, Appl. Phys. Lett. 62, 2851 (1993).

${ }^{2}$ M. Cardona, M. Weinstein, and G. A. Wolff, Phys. Rev. 140, A633 (1965).

${ }^{3}$ M. Balkanski, A. Aziza, and E. Amzallag, Phys. Status Solidi 31, 323 (1969).

${ }^{4}$ K.-F. Berggren and B. E. Sernelius, Phys. Rev. B 24, 1971 (1981).

${ }^{5}$ W. P. Dumke, Appl. Phys. Lett. 42, 196 (1983).

${ }^{6}$ K. E. Newman, A. Lastras-Martínez, B. Kramer, S. A. Barnett, M. A. Ray, J. D. Dow, J. E. Green, and P. M. Raccach, Phys. Rev. Lett. 50, 1466 (1983).

${ }^{7}$ B. E. Sernelius, K.-F. Berggren, Z. C. Jin, I. Hamberg, and C. G. Granquist, Phys. Rev. B 37, 10244 (1988).

${ }^{8} \mathrm{~J}$. Wagner and J. A. del Alamo, J. Appl. Phys. 63, 425 (1988).

${ }^{9}$ O. Zelaya-Angel, J. J. Alvarado-Gil. R. Lozada-Morales, H. Vargas, and A. Ferreira da Silva, Appl. Phys. Lett. 64, 291 (1994).

${ }^{10}$ L. Eaves, H. Vargas, and P. J. Williams, Appl. Phys. Lett. 38, 768 (1981).

${ }^{11}$ A. Mandelis, Photoacoustic and Thermal Wave Phenomena in Semiconductors (North-Holland, New York, 1987).

${ }^{12}$ H. Vargas and L. C. M. Miranda, Phys. Rep. 161, 43 (1988).

${ }^{13}$ I. Kaür, D. K. Pandya, and K. L. Chopra, J. Electrochem. Soc. 127, 943 (1980).

${ }^{14}$ A. Burger and D. Nason, J. Appl. Phys. 71, 2717 (1992).

${ }^{15}$ S. M. Sze, Physics of Semiconductor Devices (Wiley, New York, 1981), p. 15.

${ }^{16}$ S. Kolhe, S. K. Kulkarni, A. S. Nigavekar, and S. K. Sharma, Sol. Energy Mater. 10, 47 (1984).

${ }^{17}$ O. de Melo, L. Hernández, O. Zelaya-Angel, R. Lozada-Morales, M. Becerril, and E. Vasco, Appl. Phys. Lett. 65, 1278 (1994).

${ }^{18}$ K. L. Chopra, R. C. Kaaintla, D. K. Pandya, and A. P. Thakoor, Phys. Thin Films 12, $167(1987)$

${ }^{19}$ S. Toyotomi and K. Morigaki, J. Phys. Soc. Jpn. 25, 807 (1968). 